\title{
A Constituição de um Subcampo do Esporte: O Caso do Taekwondo
}

\author{
Thiago Pimenta* \\ Wanderley Marchi Jr.**
}

\begin{abstract}
Resumo: Este trabalho discute a relação do Taekwondo com o esporte moderno. Identificaram-se fatores históricos, sociais e políticos envolvidos em seu possível processo de esportivização. Optou-se pelo referencial teórico de Pierre Bourdieu e Norbert Elias. Utilizou-se a técnica de entrevista semiestruturada com os "mestres". Considerou-se: a) que evidências advindas de um processo evolutivo social não planejado formam a configuração na qual o Taekwondo assentou seu arcabouço corporal, cultural e social; b) sua divulgação como subcampo esportivo dá o valor diplomático e simbólico necessário para a divulgação de uma moral nacional garantindo sua passagem pelo mundo; c) Sua exposição alavancou um processo de imposição da nacionalidade coreana como forma de violência simbólica.
\end{abstract}

Palavras-chave: Características culturais. Esportes. Taekwondo.

\section{INTRODUÇÃO}

As artes marciais constituem-se atualmente em atividades que, em sua maioria, respondem como modalidade esportiva. Não são poucos os torneios, campeonatos e patrocinadores dispostos a oferecer distintas formas de capitais às "novas promessas" do Jiu-Jitsu, Judô, Karatê e Taekwondo. As maiores expressões dessas práticas no cenário espetacular hoje são em formatos de torneios dos chamados "vale tudo" - combates entre praticantes de artes marciais distintas - constantemente veiculados pelos meios de comunicação, especialmente pela TV.

O aumento da divulgação dessas atividades em forma de transmissões de campeonatos, contratação de comentaristas especializados,

\footnotetext{
* Mestre em Sociologia. Universidade Federal do Paraná (UFPR). CEPELS. Curitiba, Paraná Brasil. E-mail: fonsecapi@yahoo.com.br

** Doutor em Educação Física. Departamento de Sociologia da UFPR. CEPELS Curitiba, Paraná, Brasil. E-mail: marchijr@ufpr.br
} 
demonstrações de algumas técnicas em novelas e filmes é um dos fatores visíveis que aumenta a oferta desse "produto específico".

Veículos de comunicação, como a TV principalmente, tratam dessas manifestações corporais como atividades de valor filosófico, de características místicas e transcendentais, muitas vezes marginalizando os processos históricos e sociais que contribuíram para a formação desta estrutura. As artes marciais, neste caso as provenientes do Extremo Oriente, ${ }^{1}$ configuram-se em atividades de alto valor cultural devido às suas histórias particulares datadas de milhares de anos.

A partir de um processo de evolução na estrutura do pensamento, do místico ao racional (que contribuiu para a secularização das atividades corporais e consequentemente das artes marciais), do avanço do capitalismo (culminando em processos de valorização das atividades físicas como produtos específicos voltados para a acumulação de bens econômicos) e, portanto, de um crescente aumento da veiculação das atividades físicas nos meios de comunicação, as artes marciais - atividades criadas com fins primitivamente intrínsecos e locais como a defesa de território e conquistas de oportunidades e, ao mesmo tempo, a obtenção de uma forma peculiar de religiosidade adquiriram características de esporte, ou seja, visam a competição, a rivalidade, os benefícios extrínsecos e a vitória a qualquer preço. Tais características, por sua vez, desvinculam-se dos objetivos primos dessas manifestações corporais orientais, uma vez que seu embasamento é fundamentalmente religioso. ${ }^{2}$

Neste sentido, as artes marciais do Extremo Oriente, em especial, são hoje parte integrante da cultura corporal tanto quanto esporte de alto nível como, quantitativamente em menor grau, atividades que proporcionam um equilíbrio vital e a defesa pessoal do praticante. $\mathrm{O}$ presente trabalho discute a relação de uma dessas manifestações

${ }^{1}$ Enfatiza-se as artes marciais do Extremo Oriente, pois a sequência do trabalho objetivará as explicações de ordem política, social e econômica do Taekwondo, arte marcial coreana. Contudo, reconhecem-se as artes marciais que têm como origem o Oriente Médio e Ocidente como o Tahtib, arte marcial de origem egípcia, o Krav Maga, arte marcial de origem israelense e a capoeira de origem brasileira, mas embasados em referenciais místicos africanos.

${ }^{2}$ MARTA, Felipe Eduardo; PIMENTA, Thiago Farias. Os princípios filosóficos do Taekwondo no discurso dos mestres. 182 fls. Relatório final apresentado ao conselho nacional de desenvolvimento a pesquisa (CNPq) como exigência para finalização de bolsa de iniciação científica, PIBIC. Bauru: UNESP, 2001.

Movimento, Porto Alegre, v. 15, n. 01, p. 193-215, janeiro/março de 2009. 
corporais, uma prática corporal de origem coreana: o Taekwondo e sua relação com o esporte moderno.

Busca-se identificar os fatores históricos, sociais, econômicos e políticos envolvidos em seu processo de esportivização e procuramse evidências de uma possível ruptura entre os valores filosóficos orientais desta manifestação corporal para um esporte de valores capitalistas de competição e rendimento praticado hoje em 170 países com mais de 20 milhões de adeptos (KIM, 2000, p. 20), presente no quadro de modalidades de demonstração desde os Jogos Olímpicos de Seul em 1988, e inserido no quadro oficial de modalidades olímpicas nos Jogos Olímpicos de Sydney no ano de 2000.

Pretendeu-se identificar os fatores e interesses que levaram uma prática essencialmente amadora local, de buscas de benefícios intrínsecos (defesa de território, manutenção do equilíbrio vital, busca de estilo de vida pautado em preceitos filosóficos orientais), para uma prática majoritariamente espetacular, na qual a intenção é, também, a aquisição de benefícios extrínsecos (dinheiro, mercadorias, prêmios, status, capital financeiro).

Intenciona-se indicar as instituições e seus agentes específicos que procuram reger essa manifestação corporal como esporte de alto nível, observando as possíveis transformações pelas quais passou.

Procurou-se conceituar o Taekwondo e o esporte moderno no contexto social, político e econômico em que este se insere, evitando analisar tais instituições como "máquinas" independentes dos seres sociais dotados de habitus que as criaram e que as constituem.

No sentido de tornar mais completa a análise do Taekwondo, presente no contexto do esporte e, principalmente, suas possíveis forças hegemônicas, optou-se pelo referencial teórico do sociólogo francês Pierre Bourdieu e do sociólogo alemão Norbert Elias. A utilização de seus referenciais teóricos foi utilizada neste trabalho por se mostrarem pertinentes e atualizadas ao tratar das manifestações do esporte moderno e dos agentes sociais que o constituem.

Pautando a análise do objeto de estudo na teoria dos campos de Bourdieu, é possível reconhecer a existência de um campo esportivo

Movimento, Porto Alegre, v. 15, n. 01, p. 193-215, janeiro/março de 2009. 
que engloba agentes sociais, ocupantes de postos específicos que constantemente buscam, através de lutas, capitais econômicos, políticos e simbólicos.

Traçando um paralelo conceitual e metodológico, procurou-se aliar a crítica configuracional de Norbert Elias no intuito de compreender manifestações de interdependências no universo do Taekwondo, a relação social que esta arte marcial possui como agregada ao cenário esportivo e, consequentemente qual seu papel na teia de inter-relações.

Portanto, se o Taekwondo é compreendido também como esporte, consequentemente, entendendo esporte como instituição possuidora de padrões hierárquicos, econômicos, políticos e simbólicos, ou seja, como fenômeno sociologicamente inconstante procurou-se: a) analisar quais os aspectos que o definem como esporte; b) evidenciar os objetivos dos agentes dessa arte marcial em mantê-lo como esporte; c) reconhecer a posição que o Taekwondo como esporte, ocupa no espaço dos esportes; d) reconhecer as forças que o regem e o mantém no mundo dos esportes; e) descobrir evidências de uma possível acentuação da ruptura entre suas características filosóficas - religiosas - orientais para uma prática de valores capitalistas de competição e rendimento.

Apenas a revisão de literatura não responde aos objetivos propostos, já que as referências bibliográficas concernentes ao Taekwondo são limitadas no que diz respeito aos determinantes que tratam de suas transições. Neste sentido, utilizou-se a técnica de entrevista semiestruturada com os agentes responsáveis pela disseminação dessa arte marcial no País: os "mestres". Torna-se pertinente explicitar que estes seres sociais são denominados constantemente de "mestres", sendo este um atributo hierárquico elevado no interior do universo das artes marciais o que, por sua vez, denota a importância simbólica desses agentes disseminadores do Taekwondo.

\section{DelimitANDO O ESPORTE MODERNO}

Descrever a importância do esporte na sociedade moderna, exemplificando diversos fatos que possam comprová-la, pode ser um

Movimento, Porto Alegre, v. 15, n. 01, p. 193-215, janeiro/março de 2009. 
tanto perigoso, pois o risco imediato é a explicação por especulações ou por pré-noções. O fato da constante presença "esportiva" que permeia a fala do ser social acometido pelas diversas formas de transmissões esportivas por parte dos meios de comunicação de massa.

Por estar constantemente presente, desde cedo, no dia-a-dia dos indivíduos e existente "fora das consciências individuais" é que uma análise indicativa dos determinantes históricos e sociológicos do esporte torna-se difícil, pois os caminhos a serem adotados pelo pesquisador podem possuir os percalços das análises ideológicas que funcionam como limitadoras da realidade, pois "constituem elas [...] como que um véu interposto entre as coisas e nós, e que no-las mascaram tanto mais quanto julgamos mais transparente o véu" (DURKHEIM, 1968, p. 12).

Portanto, os estudos das ciências humanas referentes às manifestações do esporte moderno, em uma primeira análise, demonstram ser pertinentes na medida em que a relação entre sujeito, fenômeno esportivo espetacular e a necessidade dominante de acúmulo de capital parecem presentes e suas relações sociais modernas inseparáveis, mas, também, cabe aos estudos que se referem ao esporte como fenômeno social analisar as forças - econômicas, políticas, simbólicas - e os interesses, legitimados pelos sujeitos, que mantêm o esporte, pertinentemente, no plano do senso comum.

Destarte, pelas necessidades imprevisíveis surgidas a partir da "complexação" da configuração social, o esporte moderno, aparece como elemento de divulgação de ideais de uma classe ascendente através da secularização e racionalização dos elementos intrínsecos.

Compreende-se que a introdução do caráter racionalizado nas manifestações de jogos populares contribuiu para uma reificação das significâncias extrínsecas, contribuindo para uma ruptura entre a ludicidade e o esporte, o que Elias e Dunning (1992) classificariam como um processo cego e não planejado de longa duração.

A dificuldade de permanência das atividades corporais na esfera lúdica, mítica, contemplativa e religiosa é ocasionada pela concepção da estrutura formal burocrática que cria dependência. A complexidade social de inter-relacionamentos faz com que qualquer instituição que

Movimento, Porto Alegre, v. 15, n. 01, p. 193-215, janeiro/março de 2009. 
queira firmar-se na sociedade industrial burguesa - em especial a inglesa - "obedeça", mesmo que inconscientemente, às suas regras: "Apesar de árduos esforços dos grupos dirigentes, os encontros de alto nível são agora realizados perante grandes multidões" (ELIAS, 1992, p. 301).

A ordem da nova configuração social, garantida por agentes sociais com interesses particulares em jogo, dificilmente permite a continuidade das atividades no padrão da não seriedade, criando-se uma estrutura complexa capaz de prender qualquer ser social à sua ordem burocratizada. O que se torna pertinente é a manifestação desse poder nas distribuições de funções no interior da sociedade, no cerne dos diversos campos, as influências e confluências de interesses dos agentes na manutenção de um campo do esporte.

Para a compreensão da formação de um campo e/ou sub-campo, torna-se necessário reconhecer que a sociedade vem a ser um espaço onde os indivíduos interagem buscando formas que possam favorecêlos direta ou indiretamente.

Levando em consideração a força desta interação, é possível afirmar que esses seres sociais, mais do que interagem, são interdependentes. Retomando a idéia de configuração de Elias (1994), qualquer ação passa a influenciar - de forma negativa ou positiva na vida de outro ser social dada a complexidade da teia de interrelacionamentos criando, por sua vez, uma constelação de seres sociais interdependentes.

Associado ao caráter metodologicamente complexo de compreensão dos mecanismos sociais, associam-se as ações que os indivíduos adotam ao interagirem. Tais ações não vêm ao acaso, não são tomadas por casualidade. Os indivíduos adotam iniciativas pautadas em sua história anterior, ou seja, o que Bourdieu chama de habitus afeta e estimula as ações.

Neste sentido, uma contribuição aos estudos das manifestações esportivas na sociedade é pertinente na medida em que se torna possível articular os dois conhecimentos, tanto o objetivo quanto o subjetivo. Essa noção praxiológica pode servir para que se avance

Movimento, Porto Alegre, v. 15, n. 01, p. 193-215, janeiro/março de 2009. 
nos estudos do esporte e, porventura, contribua para a compreensão das necessidades humanas de criação de modalidades esportivas e sua apreciação, em sua utilização como meio simbolicamente consolidado e na manutenção de estruturas que corroboram sua permanência no universo das práticas que detêm poderes objetivos e simbólicos, como é o caso do Taekwondo.

Para tal, busca-se compreender os objetivos que agentes específicos de artes marciais caracterizadas por possuírem valores filosóficosorientais místicos embasados por referenciais budistas e confucionistas objetivaram a inserção dessas manifestações em um locus concorrencial de lutas características de indivíduos que visam o acúmulo de capitais como seus fins.

Concebendo o esporte como um conjunto de estruturas específicas, inter-relacionadas que se movimentam socialmente de acordo com os interesses de seus agentes, tem-se, portanto, a constituição de um espaço definido, onde estes são capazes de disputar capitais econômicos, políticos, sociais e simbólicos. Esse espaço se define como um campo de disputas, um campo concorrencial de vitórias e derrotas. "[...] esse espaço dos esportes não é um universo fechado sobre si mesmo. Ele está inserido num universo de práticas e consumos, eles próprios estruturados e constituídos como sistema" (BORDIEU, 1990, p. 211). Tal perspectiva constitui a idéia de campo.

O "campo" é detentor de uma autonomia específica, normas e regras específicas que podem e serão requeridas por seus agentes através de lutas por espaços no próprio "campo" que definirão a "conservação ou a subversão da estrutura de um capital específico".

Esta idéia remete o esporte moderno a um conjunto de práticas e consumos esportivos oferecidos aos agentes sociais para suprir uma demanda social, possuidora de valores e história própria, dotada de cronologia específica, regras e agentes.

Neste sentido, observa-se a partir de que momento há um processo de rupturas nas artes marciais coreanas de características místicas, religiosas filosóficas orientais para uma prática de valores racionais, seculares como o esporte Taekwondo.

Movimento, Porto Alegre, v. 15, n. 01, p. 193-215, janeiro/março de 2009. 


\section{SUBSÍDIOS HISTÓRICOS DAS ARTES MARCIAIS COREANAS}

A primeira dinastia que se tem notícia na Coréia é a de Kit-ze, um chinês nobre que se estabeleceu em suas planícies por volta de 1122 a.C. Em 193 a.C., outro chinês, Wiman, invadiu a região habitada pelos descendentes de Kit-ze, ocupando-a progressivamente. Em 108 a.C., toda a faixa setentrional da península estava nas mãos dos últimos invasores. Lolang tornou-se a capital da península.

As tribos que escaparam da dominação chinesa reuniram-se em três reinos: SILLA, a sudeste, fundado em 57 a.C; BAEK-JE (Paekche), na região sudoeste, fundado em 19 a.C com sua zona central próxima ao rio Han e realizava intenso comércio com o Japão e a China; e KOGURYO, na região centro-oeste, fundado em 37 d.C por Chumong. Inicialmente sua capital encontrava-se em Hwando -San, no ano de 427, posteriormente foi transferida para Pyong Yang. O chamado período dos três reinos durou até 668.

A história específica referente ao Taekwondo relata que o reino de Silla, por ser o menor entre os três reinos, encontrava-se em constante ameaça por Paekche e Koguryo até a formação de uma tropa de elite chamada Hwarang (Corpo de Flores Jovens). Criado durante o reinado de Chin Heung, vigésimo quarto rei da dinastia Silla pelo filósofo e General Kim Yu Shin, os integrantes do Hwarangdo podem ser comparados aos Samurais do Japão e aos cavaleiros medievais da Europa por sua estrutura regida por padrões religiosos, honoríficos e por serem integrantes de alta classe social. Estes recebiam uma preparação rigorosa, lenta e silenciosa, permeada por valores filosóficos de características budistas.

Esse grupo de guerreiros era treinado não apenas no uso de armas tradicionais (lanças, arco-e-flecha e espada), mas também na prática da disciplina mental, física e em várias formas de artes marciais, utilizando-se fundamentalmente dos pés e pernas.

Entre essas artes destaca-se o T'aekkion ou Tekyon. Concentrando-se em defender suas terras, os guerreiros escalavam montanhas escarpadas, nadavam em rios turbulentos nos meses frios para fortalecer seus corpos.

Movimento, Porto Alegre, v. 15, n. 01, p. 193-215, janeiro/março de 2009. 
Seu treinamento e suas vidas eram regidos por um código de honra, arraigado de valores budistas condensados em: a) obediência ao rei; b) respeito aos pais; c) lealdade para com os amigos; d) nunca recuar ante o inimigo; e) só matar quando não houvesse alternativa.

Esse rigoroso código de honra dos guerreiros Hwarang irá condicionar e dar os subsídios filosóficos/simbólicos orientais às artes marciais coreanas, que atravessaram 14 séculos até a formação da estrutura filosófica atual do Taekwondo.

Com a influência dos guerreiros Hwarang e uma aliança militar com os chineses, Silla derrotou seus rivais, conseguiu unificar o país estabelecendo o primeiro Estado coreano, Koryo, criado oficialmente em 935. Essas influências contribuíram para o estabelecimento de uma pedra espiritual que será responsável pela formação do conteúdo simbólico das subsequentes artes marciais coreanas que, de acordo com o agente disseminador do Taekwondo, "mestre" Yeo Jin Kim (2000), " [...] se desenvolveu junto com a filosofia oriental, pois dela deriva; principalmente com a influência das religiões e da cultura, como o budismo e, posteriormente o confucionismo" (KIM, 2000, p. 21).

Após a era Koryo, teve início a era Chosen, nome dado ao novo reino pelo rei Lee, Syung Gue. Esse reino perdurou por 500 anos, o que, por sua vez, não desvirtuou a prática das artes coreanas: "Nessa época a dignidade e a moral do povo coreano chegou ao seu mais alto nível" (KIM, 2000, p. 23).

Parece sensato afirmar que a filosofia oriental é o princípio que dá originalidade às suas artes marciais e que a destaca das outras manifestações corporais do Ocidente.

Com a explicação das relações entre a filosofia oriental e sua relação com as artes marciais coreanas, distingui-se sua função norteadora dos princípios que irão reger os padrões de atitudes na sociedade do primeiro Estado coreano e, mais do que isso, reconhecer também a função de tais princípios budistas e confucionistas na construção de uma identidade social, ou identidade nacional coreana e influência no seu futuro processo de ocidentalização.

Esse processo de construção é pertinentemente explicado por Dubar (2005), que coloca como a incorporação de atitudes é subjetivamente

Movimento, Porto Alegre, v. 15, n. 01, p. 193-215, janeiro/março de 2009. 
reconhecida como uma constante social que cria e modula identidades, o que, por sua vez, formará a "pedra" fundamental de inspiração de atitudes:

O que importa nesse processo é o duplo movimento pelo qual os indivíduos se apropriam subjetivamente de um "mundo social", isto é, do "espírito" (Mind) da comunidade a que pertencem, e, ao mesmo tempo, se identificam com papéis, aprendendo a desempenhálos de maneira pessoal e eficaz (DUBAR, 2005, p. 118).

Mas, além de traçar os fatores filosófico-religiosos que contribuíram para a formação desta identidade, é imprescindível definir a necessidade de sua formação, portanto, reconhecendo-a como forma simbólica de violência, pois não deixam de ser "representações mentais" em que um povo, ou mais subjetivamente, os agentes sociais, investem seus interesses, garantindo a forma pela qual cria-se um conjunto de fatores que exercem poder simbolicamente legitimado tendo a faculdade de garantir a nacionalidade coreana.

Evidencia-se na literatura (KIM, 1995; 2000; PIMENTA, 2003) um crescente processo de relacionamento entre o culto às práticas filosóficas e às artes marciais. Mas, a partir de determinado momento, essa conjunção existente entre sua prática com a filosofia oriental budista e confucionista sofrem um processo de desvirtuamento ao confrontar o conturbado passado coreano. O "caminho" das artes marciais coreanas passa a tomar um novo rumo, as regras do "jogo" a ser jogado passarão a ser diferentes.

Às artes marciais coreanas lhe são atribuídas o poder de fazer parte da construção de uma identidade nacional que durante séculos foi sendo reivindicada e construída fazendo com que houvesse uma necessidade de afirmação universal.

\section{A CONSTITUIÇÃO DE UM SUBCAMPO DO ESPORTE: O CASO DO TAEKWONDO}

Os mongóis ficaram na região da futura Coréia de 1231 a 1364. Em 1364, o General coreano Yi Taejo derrotou as forças mongóis, já

Movimento, Porto Alegre, v. 15, n. 01, p. 193-215, janeiro/março de 2009. 
enfraquecidas pela guerra que travavam com a dinastia Ming, da China. Em 1592, uma força japonesa invadiu a península coreana. Após sete anos de guerra e ocupação, os invasores foram repelidos, graças ao auxílio dado pela China novamente.

Embora a dinastia Yi permanecesse no trono, os manchus invadem o país até 1637 . Novas tentativas de penetração dos japoneses foram repelidas. Após um longo período de isolamento, em 1876 o Japão forçou a Coréia a estabelecer relações diplomáticas com o governo de Tóquio.

Em 1894, a China declarou guerra ao Japão, a qual perdurou até o ano seguinte saindo derrotada. O tratado de Shimono Seki, assinado no fim do conflito, constrangeu os chineses a renunciarem suas pretensões sobre a Coréia. Em 1905, os japoneses transformaram a Coréia em protetorado, em 1910 em colônia.

Em 1945, o Japão é obrigado a retirar-se da Coréia, pois a península fora ocupada por seus adversários ao final da II Guerra Mundial - soviéticos ao norte e americanos ao sul. No dia 8 de agosto do mesmo ano, a declaração do Cairo estabeleceu que os japoneses renderiam-se aos russos ao norte do paralelo 38 e aos norte americanos ao sul.O país fica dividido estruturalmente em Coréia do Sul de influência capitalista e Coréia do Norte de influência comunista.

A análise aprofundada destes fatores associados traz elementos para a explicação de transformações na conjuntura e formação do Taekwondo e, por consequência, de seus praticantes.

Com a derrota do Japão na II Guerra Mundial, os coreanos puderam voltar a praticar e treinar abertamente suas artes marciais como Tekyon, e, com menor ênfase o Subak, formando duelos com os estudantes que voltavam do Japão e que praticavam Karatê. Fundaram-se diversas escolas como Chong-do Kwan (a mais antiga), Mu-Duk Kwan, Ion-Mu Kwan, Chang-Um Kwan e Song-Um Kwan.

Em 1955, um grupo liderado pelo General do exército coreano Choi Hong Hi juntou esforços e conseguiu unir as diferentes escolas e estilos de artes marciais coreanas, sendo adotado o nome de

Wovimento, Porto Alegre, v. 15, n. 01, p. 193-215, janeiro/março de 2009. 
Taekwondo. ${ }^{3}$ Além da fusão de nomes padronizou-se uma seqüência de princípios e valores filosóficos que seu praticante deverá seguir: a) cortesia; b) integridade; c) perseverança; d) domínio sobre si mesmo; e) espírito indomável.

A obediência ao rei estende-se à cortesia, o respeito aos pais, transforma-se em integridade, lealdade para com os amigos passa a perseverança, nunca recuar ante o inimigo passa a ser espírito indomável, só matar quando não houvesse alternativa alarga o conceito para o domínio sobre si mesmo.

Partindo-se de uma avaliação crítica sobre a elaboração de tais princípios, é possível elucidar que os mesmos são frutos de uma mudança de cenário, têm influência de valores nacionalistas e patrióticos e, ao mesmo tempo, evidenciam uma necessidade de divulgação mundial do Taekwondo dada sua expressão no cenário político/social e econômico coreano, sendo produtos de mudanças dos antigos códigos filosóficos que regiam o Hwarang, tornando seus antigos princípios filosóficos facilmente assimiláveis.

A necessidade de tornar tais princípios mais "assimiláveis" aparentemente não corresponde a uma simples manobra estratégica de divulgação apenas, mas responde aos anseios de um grupo de agentes específicos no interior do campo das artes marciais coreanas que, cientes de uma nova conjuntura social/nacional, criaram um conjunto de normas racionais para a prática. Essa "nova necessidade" não deixa de ser fruto de um processo evolutivo social. O resultado de um processo sociogenético coreano.

Semelhante à antiga Europa medieval, a região coreana tolerara inúmeros combates pela busca de oportunidades. Diferentes células familiares disputaram entre si (mensurados desde 193 a.C) terras e formas de capitais distintos. Com a constante eliminação e agregação de oportunidades, resultando na criação de monopólios feudais e de violência, os indivíduos tornam-se mais inter-relacionados e interdependentes, o que irá contribuir para uma necessidade constante de contenção de atitudes, justamente por que tais indivíduos

${ }^{3}$ TAE significa pernas, KWON significa braços e DO significa o caminho vital pelo qual o praticante deve seguir, portanto: o caminho dos pés e das mãos.

Movimento, Porto Alegre, v. 15, n. 01, p. 193-215, janeiro/março de 2009. 
são cientes, intrinsecamente, das reações ocasionadas pelas mudanças bruscas no tabuleiro do jogo social.

A conscientização das necessidades de manutenção do equilíbrio emocional entre os indivíduos devido a uma interdependência funcional e, principalmente, entre os agentes das artes marciais coreanas, contribuiu significativamente para a formação dos cinco valores e princípios filosóficos do Taekwondo.

A "simplicidade" como a experimentamos, a oposição simples entre "bom" e "mau" e entre compassivo e cruel haviam se perdido. As pessoas encaravam as coisas com mais diferenciação, isto é, com um controle mais forte de suas emoções (ELIAS, 1994, p. 84).

Ou seja, aos agentes dos campos das artes marciais coreanas foi necessária uma adaptação às novas formas de vida sociais. As artes marciais que foram utilizadas para fins bélicos e, aliadas a uma aliança vital de preceitos encantados, começam a tomar forma de uma prática que visa ao bem estar corporal e mental individual através dos exercícios físicos e de seus valores transcendentais já que "em sociedades posteriores diferentes oportunidades, diferentes formas de vida surgiram, às quais o indivíduo tinha que se adaptar" (ELIAS, 1994, p. 202).

Portanto, a criação do esporte Taekwondo, consequentemente de seus princípios filosóficos, respeita a idéia de um processo civilizador. A mudança no cenário social coreano suscitou um novo quadro incitando os agentes do campo das artes marciais coreanas a criarem uma manifestação, modelada à conjuntura nacional. $\mathrm{O}$ Estado coreano lida com sua sociogênese. Evoluía de uma sociedade feudal repleta de células familiares dispostas a manterem e adquirirem parcelas de oportunidades para uma sociedade mais complexa embasada pelos preceitos da monetarização e da ética industrial. A obrigação do treinamento corporal visando à abstração do mundo pela elevação espiritual - características das artes marciais orientais foi sendo abandonada para dar entrada à valorização do treinamento metódico, calculado, visando a vitórias no campo esportivo.

Reproduzindo a fala de Elias, Dunning (2005) em entrevista com o professor Ademir Gebara (2005) relata que a mudança, a constante

Movimento, Porto Alegre, v. 15, n. 01, p. 193-215, janeiro/março de 2009. 
da relação do processo de civilização, não se limita pelas explicações simplificadas ou de análises unilaterais, mas engloba processos que, longe de constituírem-se em atitudes deliberadas de agentes sociais, são frutos de procedimentos sociais interdependentes:

[...] Mas o conceito de mudança social é muito mais abrangente para captá-lo, porque o que estamos descrevendo é mudança em uma direção específica, é mudança de algo relativamente simples em algo mais complexo, de algo relativamente selvagem e incontrolável para algo mais controlado, mais civilizado (GEBARA, 2005, p. 52).

Para o agente disseminador do Taekwondo, o "mestre" brasileiro Fabio Goulart (2006), a "mudança" decorre de uma necessidade advinda de processos sociais que inspiraram a divulgação do Taekwondo, processos que ocasionaram adaptações na perspectiva de seus agentes:

\begin{abstract}
A arte marcial foi criada com qual intuito? Qualquer arte marcial. Defesa do seu território, defesa de sua família e aniquilação completa do adversário ou de seu oponente. Você não pode ter isso, é que nem o gladiador. O gladiador já é um artista marcial, porque ele entrava dentro da arena e tinha que matar ou morrer, então você não pode fazer isso. Hoje em dia se criou regras pra que você consiga mostrar ao mundo como é aquela arte marcial e as pessoas praticarem. ${ }^{4}$
\end{abstract}

Elias (1994) chama a atenção para o processo de adaptação. Mas no caso das artes marciais coreanas e seus agentes, em que essa adaptação torna-se relevante? Para que universalizar uma sequência de princípios filosóficos tornando-os assimiláveis e acessíveis? A resposta a questão pode ser encontrada ao examinar-se a sequência abaixo.

Após sua criação oficial em abril de 1955, há em 1961 a reformulação do nome Taekwondo em definitivo; 1963 - Park Chunghee torna-se presidente da Coréia do Sul; 1964 - na Coréia, realiza-se

${ }^{4}$ GOULART, Fabio. "Mestre" Fábio Goulart e o Taekwondo: depoimento [jan.2006]. Entrevistador: PIMENTA, Thiago. Santos: Academia de Taekwondo Fábio Goulart, 2006. 1 cassete sonoro (30 min). Entrevista concedida para dissertação de mestrado em sociologia pela Universidade Federal do Paraná - UFPR.

Movimento, Porto Alegre, v. 15, n. 01, p. 193-215, janeiro/março de 2009. 
o primeiro campeonato mundial de Taekwondo. Em 1965 criou-se a "Korean Taekwondo Association", tendo como primeiro presidente o General Choi Hong Hi, que em 1966 fundou a International Taekwondo Fedaration (ITF), a primeira federação de Taekwondo. Em 1967 há a mudança de diretoria da associação coreana de Taekwondo. Em 1968 há a primeira competição continental asiática e inicia-se um processo de ocidentalização dessa arte marcial com sua divulgação para Europa e Estados Unidos. Em 1970 há sua introdução no Brasil. Em 1971, o presidente da Coréia do Sul, Park Chung-hee proclama o Taekwondo como esporte nacional coreano; em 1972 há a expulsão do General Choi Hong Hi da Coréia do Sul para o Canadá; em 1973 ocorre a criação da World Taekwondo Federation (WTF) por Un Yong Kim.

Percebe-se uma ordem cronológica de acontecimentos não muito distantes que caminham para um fim: a criação e legitimação de um esporte. As artes marciais coreanas saem de uma esfera bélica e contemplativa para inserir-se em um locus de concorrência por formas de apropriações de espaços definidos em um campo agora mais secular: o campo dos esportes.

As novas categorias e classes sociais emergentes presentes no interior do campo das artes marciais coreanas irão reafirmar princípios seculares no intuito de criar um novo esporte que exerça influência nos ânimos populares e, por conseguinte, faça o papel mediador e divulgador da imagem da nova Coréia, especialmente a Coréia do Sul, no intuito de desvincular-se das características de seu "país mãe", a China e seu ex-dominante, o Japão - que lhe deixou um legado cultural, inclusive nas artes marciais coreanas - e, desvincular-se da negativa imagem comunista que assolou o Ocidente.

Política mesmo queria colocar artes marciais 55, colocar uma arte marcial continuação Tekyon, Subak, tem variedades de artes marciais que existia e também no meio do tempo de dominação de japoneses que dominaram Coréia, trouxeram Karatê, então tá misturado. Então queria colocar artes marciais na Coréia que tava desenvolvendo e chegou caso de guerra do Vietnã e ficou famoso Taekwondo então parte intelectual, não sei qual cabeça que saiu pra divulgar

Movimento, Porto Alegre, v. 15, n. 01, p. 193-215, janeiro/março de 2009. 
Taekwondo como esporte. Divulgando Taekwondo pra divulgar Coréia, divulga esporte divulga Coréia. ${ }^{5}$

Para Bourdieu (2005, p. 138), há uma razão para os agentes realizarem determinadas atitudes:

[...] razão que se deve descobrir para transformar uma série de condutas aparentemente incoerentes, arbitrárias, em uma série coerente, em algo que se possa compreender a partir de um princípio único ou de um conjunto coerente de princípios. Nesse sentido, a sociologia postula que os agentes sociais não realizam atos gratuitos.

O reconhecimento do Taekwondo como modalidade esportiva e sua consideração pelo Comitê Olímpico Internacional (C.O.I) em 1980 dão o elemento necessário para sua afirmação oficial no campo esportivo de alto rendimento, pois exerce uma violência simbólica sobre seus espectadores, praticantes e nos praticantes de outras artes marciais, uma vez que a aquisição do status de esporte nacional e de esporte olímpico é legitimado pelos mecanismos legais que amparam a existência de um campo esportivo, por sua vez, de um sub-campo do esporte.

[...] eu não conheço no Brasil hoje ninguém que treina Taekwondo como arte marcial, porque treinar o esporte como arte marcial requer uma série de rotinas que não se praticam mais, por exemplo, antigamente a gente calejava as mãos, de alguma maneira prepara a musculatura do abdome e antebraço, a gente batia antebraço contra antebraço e além de tudo lutava muito sem colete, sem proteção. O Taekwondo praticado como arte marcial ele é pesado ele machuca e como esporte até que não, porque você usa as proteções, tem técnicas modernas e tal. ${ }^{6}$

${ }^{5}$ BANG, Kun. "Mestre" Kun Mo Bang e o Taekwondo: depoimento [out.2003]. Entrevistador: MARTA, Felipe. Marília: Academia Bang, 2003. 1 cassete sonoro (30 min). Entrevista concedida para monografia de conclusão da graduação em Educação Física pela Universidade Estadual de São Paulo - UNESP/Bauru. 2006

${ }^{6}$ NEGRÃO, Carlos. "Mestre" Carlos Negrão e o Taekwondo: depoimento [mai. 2006]. Entrevistador: T. F. F. Pimenta. São Paulo: DEF Baby Barion, 2006. 1 cassete sonoro (30 min). Entrevista concedida para dissertação de mestrado em sociologia pela Universidade Federal do Paraná - UFPR. 2006.

Movimento, Porto Alegre, v. 15, n. 01, p. 193-215, janeiro/março de 2009. 
Neste caso, "mestre" Carlos Negrão (2006) expõe que o Taekwondo treinado de forma rigorosa, ou seja, "calejando-se as mãos e os pés" demonstra a forte ligação com um treinamento bélico ou marcial. Esta "antiga" forma de treinamento parece ser a ligação entre as remotas artes marciais coreanas com o Taekwondo.

A mudança do nome para Taekwondo marcou o nascimento de uma manifestação corporal e cultural tipicamente coreana. É nesse interesse - também - que os agentes deste campo específico firmaram a idéia de um Taekwondo esportivo.

Esse investimento de capitais econômicos, simbólicos e sociais por parte de um grupo de agentes do campo das artes marciais coreanas resultou na afirmação do Taekwondo como esporte, uma vez que "[...] o investimento num campo resulta da interação entre um espaço de jogo que define os desafios e um sistema de disposições adequado a este jogo" (BOYER, 2005, p. 278).

Com todo processo histórico/social explicitado até a formação do Taekwondo, percebe-se que essa nova instituição não deixou de ser mantida pelos detentores da maior quantidade de capitais econômicos, sociais, culturais e simbólicos. Tais estruturas dão contribuições para o reconhecimento de ações inter-relacionais, que levaram o Taekwondo a ser reconhecido como um subcampo do esporte.

É neste sentido que os agentes deste recém constituído subcampo irão afirmar uma necessidade em definir-se novos princípios ao Taekwondo, devido ao seu já estabelecimento como esporte:

\begin{abstract}
Situação meio difícil quando eu aprendi Taekwondo, quando eu trouxe Taekwondo pro Brasil eu pensava que era artes marciais, mas depois entrou esse federação mundial que Un Yong Kim dirigiu, virando esporte. Hoje Taekwondo é esporte. Com esse mudança filosofia também tem que mudar, eu acho. [...] Eu, ainda hoje, tenho dúvidas se nós temos filosofia ou não, certo? ${ }^{7}$
\end{abstract}

\footnotetext{
${ }^{7}$ BANG, Kun. "Mestre" Kun Mo Bang e o Taekwondo: depoimento [out.2003]. Entrevistador: MARTA, Felipe. Marília: Academia Bang, 2003. 1 cassete sonoro (30 min). Entrevista concedida para monografia de conclusão da graduação em Educação Física pela Universidade Estadual de São Paulo - UNESP/Bauru. 2006.
}

Movimento, Porto Alegre, v. 15, n. 01, p. 193-215, janeiro/março de 2009. 
Tal estratégia não delineou um caminho abstrato. Não se pode tomar essa tática como uma atitude substancialista criada e movimentada pelo próprio movimento. $\mathrm{O}$ movimento das ideias na teia de inter-relacionamentos e interdependências do campo jurídico, político, esportivo, do campo das artes marciais coreanas e do campo do Taekwondo foi dado por um grupo de agenciadores de capitais, liderados por um indivíduo com o objetivo de divulgar o país Coréia.

Todo processo de criação do Taekwondo - reconhecendo-se como processo não apenas o desenrolar recente de denominação, mas a sociogênese - caminhou para a formação de um espaço dos possíveis. No espaço das subjetividades, reconhece-se este um dos possíveis como o lugar funcional no qual se averiguam os imperativos simbólicos associados aos valores adquiridos:

O espaço dos possíveis característico de cada campo, religioso, político ou científico etc., funciona, e virtude do princípio de divisão (nomos) específico que o caracteriza, como um conjunto estruturado de licitações e de solicitações e também de interditos; ele atua como uma língua, como sistema de possibilidade e de impossibilidades de expressão que proíbe ou encoraja processos psíquicos diferentes entre si e inteiramente diferentes dos do mundo cotidiano; [...] (BORDIEU, 2005, p. 16).

Sua criação deu margem à formação de um recente campo de trabalho, aumentando o alcance de atuação das manifestações corporais e da cultura coreanas, incluindo seus princípios e valores inspirados pela ética religiosa oriental.

Esses princípios, ou valores religiosos/filosóficos, por necessidade, sustentam a formação de recentes estruturas de valores atualizadas por uma conjuntura social/política recente da sociedade coreana, levando-se a afirmar que esses valores sofreram uma ruptura.

O desenvolvimento de um lado espiritual pela arte marcial tornase uma busca secular de apropriação de títulos e bens objetivos e simbólicos, encontrando no esporte o meio funcional para tal.

Movimento, Porto Alegre, v. 15, n. 01, p. 193-215, janeiro/março de 2009. 


\section{CONSIDERAÇõES}

A ciência de um campo esportivo, associada à ideia de teias de interdependência, traz a noção de movimento aos campos. Nesse sentido, têm-se os agenciadores de capitais que, além de encontraremse constantemente em conflitos por apropriações, permanecem na dependência das atitudes de outros agentes, pois dada a complexidade da estrutura de seus campos, cada movimento em seu interior acarreta uma consequência, negativa ou positiva, a partir do ponto de vista social em que se encontra determinado agente.

A noção de campo esportivo, inserida na compreensão do Taekwondo como expressão corporal historica e socialmente construída, dá margem à ideia de um subcampo do esporte. É neste sentido que o presente estudo concentrou suas análises que, ao longo do trabalho, foram sendo confirmadas ao Taekwondo. Análises estas que perpassaram as idéias de habitus, agentes, capitais, poder e interesses.

Essas evidências advindas de um processo evolutivo social não planejado irão formar a estrutura na qual o Taekwondo assentou seu arcabouço corporal, cultural, econômico, político e social, na medida em que seu desenvolvimento evidencia um processo social de longa duração.

A hipótese inicial de que o Taekwondo é uma arte marcial nascida de uma ruptura com os valores religiosos filosóficos não foi corroborada.

Ao Taekwondo é atribuída uma trajetória recente. De acordo com a literatura, seu "ano oficial de criação" é 1955. A palavra "oficial" carrega um possível processo de ruptura; de uma arte marcial de valores bélicos, religiosos e contemplativos para um esporte de rendimento no qual a procura da maximização de resultados torna-se a busca de seus praticantes. Mas, ao analisarem-se as entrevistas, inspirando-se na ideia de campo e à luz de uma compreensão referente a um processo civilizador responsável pela constituição de um subcampo esportivo, apreende-se que a palavra "oficial" poderia ser retirada dos registros referentes à sua criação. O Taekwondo foi criado como uma modalidade esportiva, foi criado para ser esporte.

Movimento, Porto Alegre, v. 15, n. 01, p. 193-215, janeiro/março de 2009. 
Processos de rupturas entre valores religiosos filosóficos coreanos ocorreram, mas ao Taekwondo esses valores podem ser caracterizados como continuidades ou prosseguimentos, uma vez que a ruptura dos valores sociais coreanos, permeados pelos referenciais religiosos para uma estrutura de pensamento permeada pela competição industrial regrada, burocratizada, institucionalizada não é o resultado de uma ação estratégica por parte dos agentes desta arte marcial, mas o resultado de um processo evolutivo social cego, não planejado.

Ele foi fundado como manifestação corporal esportiva no intuito de alavancar um processo de valorização social através de sua estrutura simbólica específica dada a história de seu país de origem ter sido permeada por uma série de conflitos belicosos.

A divulgação de um esporte coreano dá o valor simbólico necessário para a publicação e o desenvolvimento de uma moral nacional. O caráter diplomático do esporte garante sua passagem pelo mundo assegurando sua transmissão como produto reconhecidamente pátrio, juntamente com o apoio governamental que deixa explícita a necessidade de uma divulgação mundial. Vitória de um grupo de agentes que via a importância nacional e pessoal em fazer parte de um sub-campo esportivo responsável pela divulgação da imagem da nova Coréia capitalista - Coréia do Sul.

A exposição do Taekwondo alavancou um processo de imposição da nacionalidade coreana. Uma forma de violência simbólica exigida como necessidade constante. Os locais de treinamento espalhados pelo planeta, a importância em realizar as contagens dos golpes ou dos exercícios em língua coreana e a necessidade de saudação de sua bandeira nacional são manifestações desta imposição.

Os valores que regiam os praticantes do Tekyon deveram sua transformação a um processo de adaptação e uniformização de atitudes, no qual o processo de interdependência entre os indivíduos tornou-se mais sólido.

A criação de princípios filosóficos ao Taekwondo liga-se com um passado de submissão às manifestações religiosas que um conjunto de seres sociais deveria seguir.

Movimento, Porto Alegre, v. 15, n. 01, p. 193-215, janeiro/março de 2009. 
Mostrar ter conhecimento de atos como esses, sem reconhecer o sentido do jogo ao qual se insere este grupo de agentes específicos, é arranhar a superfície do processo. Em Bourdieu foi possível superar essa perspectiva buscando-se "o sentido do jogo social". Sentido do jogo criado pelo habitus do sentido do jogo. Ter este sentido é tê-lo na pele; é perceber no estado prático seu futuro; é ter o senso histórico do jogo.

A visão desses processos como um "jogo a ser jogado" confirma a ideia de movimento no interior dos campos, especificamente, no interior do campo das artes marciais coreanas até sua fusão como um subcampo esportivo. Esses movimentos, longe de serem desprovidos de interesse, constituíram a linha de interpretação que conduz o pesquisador a reconhecer nesta arte marcial seu caráter social e de construção de identidades que hoje, reproduz sua imagem esportiva dominante.

Portanto, é preciso pensar o Taekwondo como pertencente a um campo esportivo. Não apenas reconhecer seus atributos técnicos, econômicos, sociais e simbólicos que garantem sua permanência no espaço dos esportes, mas reconhecer o movimento específico, iniciado por agentes com interesses definidos no interior do campo das artes marciais coreanas, inspirados por um processo sociogenético e que levou esta recente prática a consolidar-se como esporte.

The taekwondo case: the constitution of a subfield of the sports

Abstract: The present work discusses the relation

of Taekwondo with modern sports. Historical, social and political elements involved in an eventual process of "sportivization" were identified. The option was to work with the theoretic referential of Pierre Bourdieu and Norbert Elias and also a semi- structured technique interview with the masters was used. Considerations: a) its evidences occurred to a social evolutionary process not planned, created the configuration in which Taekwondo placed its corporal, cultural and social framework. b) its diffusion as a sports sub field offers the diplomatic and symbolical necessary values towards a diffusion of a national moral that confirms its entry to the world. c) its exposition led off to an imposing process of the corean nationality as a symbolic violence aspect.

Keywords: Cultural characteristics. Sports. Taekwondo.

Movimento, Porto Alegre, v. 15, n. 01, p. 193-215, janeiro/março de 2009. 


\begin{abstract}
La constitución de un sub campo del deporte: el caso de taekwondo

Resumen: El trabajo presente discute la relación de

Taekwondo con lo deporte moderno. Históricos, sociales y políticos elementos implicados en un proceso eventual de esportivización se identificaron. La opción fue trabajar con el referencial teórico de Pierre Bourdieu y Norbert Elias y también un medido estructurado de técnica se utilizó. Las consideraciones: a) sus evidencias ocurrieron a un proceso evolutivo social no planeado, creó la configuración en la que Taekwondo colocó a su cabo, armazón cultural y social. b) su difusión como un sub-campo de deporte ofrece los valores diplomáticos y simbólicos necesarios hacia una difusión de una moral nacional que confirma su entrada al mundo. c) su exposición empezó a un proceso imponente de la nacionalidad coreana como un aspecto simbólico de violencia.
\end{abstract}

Palabras-clave: Caracteristicas culturales. Deportes. Taekwondo.

\title{
REFERÊNCIAS
}

BOURDIEU, Pierre. Coisas ditas. São Paulo: Brasiliense, 1990.

. As contradições da herança. In: Cultura e subjetividade: saberes nômades. Campinas: Papirus, 2005, p. 7-18.

O poder simbólico. Rio de Janeiro: Bertrand Brasil, 2004.

Razões práticas: sobre a teoria da ação. Campinas: Papirus, 2005.

BOYER, Robert. A arte do Judoca. In: ENCREVÉ, P; LAGRAVE, R. Trabalhar com Bourdieu. Rio de Janeiro: Bertrand Brasil, 2005, p. 271-283.

DUBAR, Claude. A socialização: construção das identidades sociais e profissionais. São Paulo: Martins Fontes, 2005.

DURKHEIM, Émile. As regras do método sociológico. São Paulo: Nacional, 1968.

ELIAS, Norbert. O processo civilizador: formação do estado e civilização. 2.ed. Rio de Janeiro: Jorge Zahar, 1993, v. 2.

. O processo civilizador: uma história dos costumes. Rio de Janeiro: Jorge Zahar, 1994. v. 1.

Movimento, Porto Alegre, v. 15, n. 01, p. 193-215, janeiro/março de 2009. 
ELIAS. Norbert; DUNNING, Eric. A busca da excitação. Lisboa: Difel, 1992.

GEBARA, Ademir. Conversando sobre Norbert Elias: depoimentos para uma história do pensamento sociológico. Piracicaba: Bisccalchin, 2005.

KIM, Yeo Jim. Taekwondo: arte marcial coreana. São Paulo: Thirê, 1995. v. 1.

Taekwondo: arte marcial coreana. São Paulo: Thirê, 2000, v. 2.

LINS, Daniel et al. (Org). Cultura e subjetividade: saberes nômades. Campinas: Papirus, 2005.

PIMENTA, Thiago Farias. A constituição de um sub-campo de esporte: o caso do Taekwondo. 2007. Dissertação (Mestrado) - Ciências Sociais, Departamento de sociologia, UFPR, Curitiba, 2007.

PIMENTA, Thiago Farias. O Taekwondo no contexto olímpico na oralidade dos mestres. Monografia (Graduação) - Educação Física, Departamento de Educação Física, UNESP, Bauru, 2003.

Recebido em: 23/09/2007

Aprovado em:18/02/2008

Movimento, Porto Alegre, v. 15, n. 01, p. 193-215, janeiro/março de 2009. 